Marketplace is provided as a service to readers using text and images from the manufacturer, supplier or distributor and does not imply endorsement by Vital. Normal and prudent research should be exercised before purchase or use of any product mentioned.

\title{
TREASURE TROVE AT BDTA SHOWCASE
}

The BDTA Dental Showcase is to return to the NEC, Birmingham on 12-14 November 2009 with the theme 'Treasures of Dentistry'. For the first time, members of the dental team who attend will be able to gain verifiable $\mathrm{CPD}$ hours by reading and answering questions on a selec-

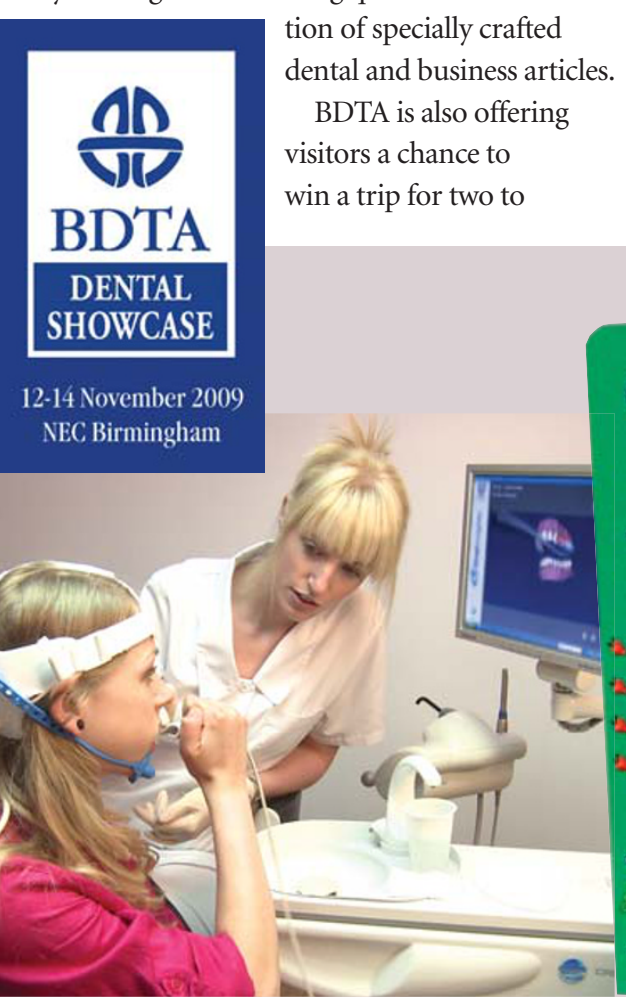

\section{PREVENTATIVE CARE TECHNOLOGY}

PracticeWorks have added Oralinsights to their portfolio, a product that maps out an individual patient's dentition and their brushing techniques. Using the innovative application of technology, it creates a 3D image of each patient's individual dentition and allows a hygienist to illustrate the areas of the mouth that require more attention when brushing.

Educational visual feedback is simultaneously provided whilst the patient brushes giving comprehensive information. The system produces a report which indicates what improvements could be made in which areas of the mouth. Oralinsights has been shown to develop children's motivation for brushing, and the effects of the initial appointment have proven to last as long as a year. For more information please call 08001699692 or visit www.practiceworks.co.uk.
Treasure Beach Hotel in Barbados. Just register in advance for your complimentary ticket by visiting www.dentalshowcase.com, calling the registration hotline on 01494729959 or texting your name, postal address, occupation and GDC number to 07786206276.

The winning entry will be selected at random after the exhibition has closed on 14 November 2009. Advance registration closes on 6 November 2009 and on-the-day registration is $£ 10$ per person.

\section{IMPROVE PATIENT EXPERIENCE}

Smile-on has the tools you need to comply with the Healthcare Commission's standards. The Clinical Governance programme has been designed to correspond with the Standards for Better Health (Department of Health, 2004).

An introductory seminar, comprehensive workbook and 90-minute CD-ROM and/or online course, enables dental practices to comply fully with the clinical governance agenda.

Using the proven Plan-Do-Study-Act strategy, the programme helps dental teams to improve patient experience and satisfaction, reduce the scope for error, promote evidence-based care and encourage the involvement of the whole team.

For more information please call Smile-on on 02074008989 or email info@smile-on.com. 